\section{Лесоводственная оценка естественного возобновления и формирование насаждений на сплошных вырубках}

\author{
В. А. Ряхин ${ }^{1}$ \\ В. А. Ананьев \\ Петрозаводский государственный университет \\ Институт леса КНЦ РАН
}

Рассматриваются результаты исследования естественного возобновления на сплошньх вырубках изпод сосновьх и еловых древостоев брусничных и черничнњх типов леса. Очерчен круг проблем и предполагаемых направлений их решения.

Ключевые слова: естественное возобновление, сплочные вырубки, черничные и брусничные типы леса.

\section{ВВЕДЕНИЕ}

Леса в отличие от других природньх ресурсов обладают способностью восстанавливаться естественньм путем. Процесс естественного возобновления. сплошных вырубок зависит от множества факторов: климатических, гидрологических, почвенных условий, типов леса, экспозиции склонов, наличия источников обсеменения, степени задернения почвы и т. д. Леса естественного происхождения являются основным производителем всех важнейших полезнъх функций. Преимущества естественного возобновления с точки зрения биологии и экономики подчеркивали Г. Ф. Морозов, И. С. Мелехов, В. П. Тимофеев [1].

Естественное возобновление, особенно при использовании сохранившегося при главной рубке подроста, намного сокращает сроки выращивания леса, снижает затраты труда и средств по сравнению с искусственнњм лесовосстановлением. При этом в ряде случаев формируются насаждения с более высокими наследственными свойствами, сохраняются благоприятные водно-физические свойства почвы. Ход возобновления леса на вырубках характеризуется большим различием в отношении продолжительности самого процесса и конечного результата - формирования состава и густоты молодняка. В зависимости от лесорастительньх условий возобновление растягивается до 15-20 лет, а иногда и более и происходит как за счет хвойньх, так и лиственных пород [2].

В Карелии, начиная с $50-x$ годов в связи с резким увеличением объема лесозаготовок и невозможностью создания лесньх культур на всей площади годичной лесосеки, большое внимание уделялось со-

\footnotetext{
${ }^{l}$ Авторы - соответственно дочент, зав. кафедрой лесного хозяйства и $\mathrm{cm}$. науч. сотрудник Института леса
}

(C) В. А. Ряхин, В. А. Ананъев, 1999 хранению подроста. Это лесохозяйственное мероприятие не утратило своего значения в деле лесовосстановления в республике и в настоящее время, когда на $50 \%$ площади вырубок лесовозобновление осуществляется путем сохранения подроста.

Сокращение размеров лесосек по площади до 50 га и проведение мер содействия естественному возобновлению будут способствовать более успешному восстановлению хозяйственно ценньх пород на сплошньх вырубках. Это очень важно, поскольку экономические условия в настоящее время не позволяют надеяться только на лесокультурную практику.

\section{МЕТОДИКА И РЕЗУЛЬТАТЫ ИССЛЕДОВАНИЯ}

В 1981 - 1995 годах на территории Костомукшского, Воломского, Сумского, Ледмозерского, Олонещкого и Петрозаводского лесхозов обследовано 38 вырубок сосняков и ельников давностью рубки от 2 до 25 лет, где возобновление происходило естественным путем. Площадь вырубок колебалась от 5-8 до 20-26 га. Разработка лесосек велась в основном методом узких пасек с сохранением подроста. Валка осуществлялась бензопилой "Урал", трелевка хлыстов - трактором ТДТ-55. На отдельных лесосеках оставлены групшы обсеменителей или отдельные семенники. Другие лесосеки ввиду мелкоконтурности предполагались к обсеменению от стен леса.

Детальная оценка возобновления проводилась на учетных площадках размером от 4 до 25 м $^{2}$ (в зависимости от высоты подроста), которые равномерно распределялись на исследуемьх участках. Количество учетньх площадок варьирует от 30 до 100 штук и зависит от густоты и равномерности размещения подроста по вырубке. При натурньх работах учитывали состояние подроста, его распределение по породам и группам высоты, генерациям. Кроме того, в пределах каждой высотной групшы были взяты учетные деревца, на которых проведены измерения годичньх приростов по высоте.

На стационарных пробных площадях с давностью рубки 25 лет и более производился перечет деревьев по элементам леса и ступеням толщины. Для построения графика высот по каждой породе измерялись высоты по ступеням толщины. Основные таксационные показатели древостоев определялись по существующим методам, применяемым в лесной таксации.

Значительная часть спельх и перестойных насаждений имеет невысокую полноту (0,6 и менее), что способствует появлению и развитию подроста под пологом леса. В зависимости от условий местопроизрастания в спельх и перестойньх еловьх древостоях Карелии количество подроста варьирует от 1,8 до 7,6 тыс. шт/га. Под пологом сосняков брусничньх и черничных имеется соответственно $1-5$ и 0,5 - 1,5 тыс. шт/га жизнеспособного подроста сосны 
[1]. Исследованиями и практикой доказана возможность сохранения подроста при соблюдении технологии разработки лесосек до $60-70 \%$ от общего количества до рубки.

Изменившиеся после сплошных рубок условия роста оказывают существенное влияние на устойчивость и состояние подроста. На всех обследованньх участках отмечено наличие нежизнеспособного подроста, доля которого составляет $8-27 \%$ от общего количества. Наибольший отпад наблодался на вырубках с преобладанием мелкого подроста. Это объясняется длительным пребыванием мелких экземпляров сосны под снеговым покровом и повреждением их фацидиозом (снежным шютте).

Соотношение количества подроста предварительной и последующей генераций зависит от многих факторов: наличия подроста под пологом материнского древостоя и его размера, технологии и сезона рубки, применяемой техники, давности рубки и т. Д. На свежих вырубках 2-летней давности количество предварительного подроста варьирует от 410 до $1050 \mathrm{mrт} /$ га, а на старьх (13-17-летней давности) от 150 до 920. Распределение хвойного подроста по породам и генерациям в зависимости от давности рубки приведено в табл. 1.

С увеличением давности рубки сосновых лесов происходит постепенное накопление подроста последующей генерации за счет налета семян от оставленных семенников и стен леса. Необходимо отметить, что общее колигество хвойного подроста предварительной генерации на вырубках из-под сосняков черничныг и брусничньгх варьирует в очень широких пределах (от 150 до $1520 \mathrm{mT} /$ га), однако его явно недостаточно для успешного облесения вырубленной территории. Необходимы меры содействия естественному возобновлению, чтобы за счет подроста последующей генерации значительно увеличить густоту хвойного подроста и тем самым составить конкуренщию лиственным породам, которые в большом количестве появляются на вырубках.

Важньм показателем в характеристике естественного возобновления является распределение подроста по группам высоты. Чем выпе хвойный подрост, тем сильнее он способен противостоять негативному воздействию со стороны березы и осины, обладающих в молодом возрасте большим приростом в высоту по сравнению с сосной и елью. Динамика распределения подроста по категориям крупности приведена в табл. 2.

На свежих вырубках преобладает мелкий подрост, а к моменту смыкания молодняка - средний и крупный. Однако в этом возрасте лиственные породы уже обгоняют по высоте хвойные, поэтому при преобладании в составе древостоя первых требуется проведение рубок ухода для создания более благоприятньх условий для дальнейшего роста и развития хвойньх растений.
Прирост по высоте подроста зависит от его размера и времени появления. Крупный подрост (старше 1825 лет ), появившийся под пологом материнского древостоя, после рубки испытывает воздействие резко изменившихся условий среды и в течение 35 лет и более и снижает темпы прироста. После адаптации величина годичного прироста у подроста доходит до 13-17 см (через 10 лет после рубки) и 15-25 см (через 15-17 лет). Величина годичного грироста по высоте у среднего и мелкого подроста составляет соответственно $10-16$ и 6-10 см, причем наблюдается постоянное увеличение этого показателя.

Состав формирующихся на вырубках молодняков зависит от многих факторов как природного, так и антропогенного характера. На вырубках из-под сосняков брусничньх доля сосны колеблется от 1 до 6 единиц, в сосняках черничньг - от 1 до 5. Столь значительные различия в составе молодняков определяются количеством подроста, сохранившегося в результате рубки, наличием семенников на вырубке, степенью минерализации почвы, количеством урожайньх лет за прошедший с момента рубки период, размером делянки, составом древостоев, примыкающих к вырубке и др.

В целом можно отметить, что на свежих вырубках присутствует недостаточное количество хвойного подроста. В дальнейшем при ітоявлении подроста последующей генерации и наличии надлежащих условий для его роста и развития складывается картина, позволяющая оценить естественное возобновление как успешное. Для формирования чистых по составу сосновых древостоев брусничных типов леса необходимо 4-5 тыс. шт/га жизнеспособного подроста.

Изучение естественного возобновления на вырубках с давностью рубки 25 лет и более позволяет выявить закономерности и дать прогноз хода роста и формирования насаждений из подроста и наметить лесохозяйственные мероприятия, способствующие выращиванию хвойньхх насаждений.

На обследованной вырубке из-под ельника черничного после сплошной рубки в 1956 году насчитывалось до 2400 экземпляров елового подроста на 1 га. Данные, характеризующие предварительное возобновление на вырубке в год рубки и через 17 лет после нее, приведены в табл. 3.

Подрост различен по высоте и возрасту. Возраст его колеблется в очень широких пределах - от 3 до 140 лет (коэффициент вариация возраста равен 4050\%). Ель в возрасте 35-60 лет имеет высоту 1-3 м и относится к категории среднего и крупного подроста. Представленность елового подроста различным возрастом будет в дальнейшем способствовать формированию разновозрастньх насаждений.

Распределение подроста по группам высот неравномерное. На данном участке наиболее представлен 
мелкий подрост (высотой до 0,5 м), с увеличением высоты численность елового подроста снижается. Через 17 лет после рубки материнского древостоя в распределении подроста ели по высоте произошли существенные изменения. Количество подроста высотой более 2 м увеличилось и составило 620 шт/га (29\%). Улучшение условий роста в результате вырубки материнского древостоя способствовало интенсификации прироста по высоте и по диаметру у подроста и скорейшему достижению перечетньх размеров и переходу его в основную часть древостоя. Количество подроста перечетньх размеров (с диаметром более $6 \mathrm{cm)} \mathrm{возросло} \mathrm{до} 31 \%$. Этот подрост имеет высоту более 4 м и превышает березу, появившуюся в год рубки. В отпад перешло 260 экземпляров на 1 га, что составило $11 \%$ от общего количества подроста.

Последующие наблюдения за динамикой роста и развития древостоя показали, что на вырубке из-под ельника черничного через 25 лет из подроста предварительного возобновления сформировалось высокополнотное насаждение с составом $8 \mathrm{E} 25+\mathrm{C}$ со средним диаметром 9,5 см, высотой 7,2 м, общим запасом $62 \mathrm{~m}^{3} /$ га. Древостои из подроста обладают повышенной энергией роста, о чем свидетельствует текущий прирост по площади сечения и запасу, равный соответственно 9,1 и 8,3\%. Средняя высота древостоев, сформировавшихся из подроста, больше на $50 \%$, а средний диаметр в 2,2 раза выше, чем в древостоях нормального ряда развития [3].

\section{ЗАКЛЮЧЕНИЕ}

Приведенные исследования показали, что в северной части Карелии на вырубках из-под сосновьх древостоев процесс естественного возобновления протекает довольно успешно. Сохранение подроста на вырубках из-под еловьх насаждений обеспечивает непрерывное лесопокрыгие, устойчивое развитие древостоев, сокращает сроки выращивания наиболее ценной древесины хвойных пород и отвечает основньг положениям закона об охране природы.

\section{ЛИТЕРАТУРА}

1. Виликайнен М. И., Зябченко С. С., Казимиров Н. И. Естественное возобновление леса в Карелии // Вопросы лесоведения и лесоводства в Карелии. Петрозаводск, 1975. С. 4-12.

2. Зябченко С. С., Виликайнен М. И. Рубки и восстановление сосновьг лесов // Сосновые леса Карелии и повышение их продуктивности. Петрозаводск, 1974. С. 85-182.

3. Лесотаксационные таблицы / Карельское лесоустроительное предприятие; Институт леса КФ АН СССР. Петрозаводск, 1976. 32 с.

Характеристика естественного возобновления на вырубках

Таблища 1 из-под сосняков брусничных и черничных

\begin{tabular}{|c|c|c|c|c|c|c|c|c|}
\hline Давность & \multirow{2}{*}{ Тип леса } & \multirow{2}{*}{ Генерация } & \multicolumn{2}{|c|}{ Сосна } & \multicolumn{2}{|c|}{ Ель } & \multicolumn{2}{|c|}{ Хвойные } \\
\cline { 4 - 8 } & & & шт/га & $\%$ & шт/га & $\%$ & шт/га & $\%$ \\
\hline 2 & \multirow{2}{*}{ брусничный } & предварительная & 560 & 40,3 & 30 & 18,8 & 590 & 38,1 \\
& & последующая & 830 & 59,7 & 130 & 81,2 & 960 & 61,9 \\
\hline 2 & \multirow{2}{*}{ черничный } & предварительная & 410 & 40,6 & 290 & 30,2 & 700 & 35,5 \\
& & последующая & 600 & 59,4 & 670 & 69,8 & 1270 & 64,5 \\
\hline 8 & \multirow{2}{*}{ черничный } & предварительная & 80 & 2,5 & 260 & 6,6 & 340 & 4,8 \\
& & последующая & 3120 & 97,5 & 3650 & 93,4 & 6770 & 95,2 \\
\hline 15 & \multirow{2}{*}{ брусничный } & предварительная & 130 & 3,1 & 1020 & 20,6 & 1150 & 12,6 \\
& & последующая & 4060 & 96,9 & 3920 & 79,4 & 7980 & 87,4 \\
\hline
\end{tabular}


Таблица 2

Распределение подроста по группам высоты

\begin{tabular}{|c|c|c|c|c|c|c|c|c|c|c|}
\hline \multirow{2}{*}{$\begin{array}{l}\text { Дав- } \\
\text { ность } \\
\text { рубки } \\
\end{array}$} & \multirow[t]{2}{*}{ Тип леса } & \multirow{2}{*}{$\begin{array}{c}\text { Категория } \\
\text { подроста }\end{array}$} & \multicolumn{2}{|c|}{ Сосна } & \multicolumn{2}{|c|}{ Ель } & \multicolumn{2}{|c|}{ Хвойные } & \multicolumn{2}{|c|}{ Лиственные } \\
\hline & & & штт/га & $\%$ & шт//гa & $\%$ & шт/га & $\%$ & шт/гa & $\%$ \\
\hline 2 & $\begin{array}{l}\text { сосняк } \\
\text { брусн. }\end{array}$ & $\begin{array}{l}\text { мелкий } \\
\text { средний } \\
\text { крупный }\end{array}$ & $\begin{array}{r}830 \\
480 \\
80 \\
\end{array}$ & $\begin{array}{r}59,7 \\
34,5 \\
5,8 \\
\end{array}$ & $\begin{array}{r}130 \\
30 \\
- \\
\end{array}$ & $\begin{array}{c}81,2 \\
18,8 \\
-\end{array}$ & $\begin{array}{r}960 \\
510 \\
80 \\
\end{array}$ & $\begin{array}{r}61,9 \\
32,9 \\
5,2\end{array}$ & $\begin{array}{l}2010 \\
- \\
-\end{array}$ & $\begin{array}{l}100 \\
- \\
-\end{array}$ \\
\hline 2 & $\begin{array}{l}\text { сосняк } \\
\text { черн. }\end{array}$ & $\begin{array}{l}\text { мелкий } \\
\text { средний } \\
\text { крупный }\end{array}$ & $\begin{array}{r}600 \\
320 \\
90 \\
\end{array}$ & $\begin{array}{r}59,4 \\
31,7 \\
8,9 \\
\end{array}$ & $\begin{array}{r}670 \\
230 \\
60 \\
\end{array}$ & $\begin{array}{r}69,8 \\
24,0 \\
6,2 \\
\end{array}$ & $\begin{array}{r}1270 \\
560 \\
150 \\
\end{array}$ & $\begin{array}{r}64,5 \\
27,9 \\
7,6 \\
\end{array}$ & $\begin{array}{c}1480 \\
- \\
- \\
\end{array}$ & $\begin{array}{c}100 \\
- \\
- \\
\end{array}$ \\
\hline 8 & $\begin{array}{l}\text { сосняк } \\
\text { черн. }\end{array}$ & $\begin{array}{l}\text { мелкий } \\
\text { средний } \\
\text { крупный }\end{array}$ & $\begin{array}{c}2020 \\
1100 \\
80\end{array}$ & $\begin{array}{r}63,1 \\
34,4 \\
2,5 \\
\end{array}$ & $\begin{array}{r}1070 \\
2540 \\
300 \\
\end{array}$ & $\begin{array}{r}27,4 \\
64,9 \\
7,7 \\
\end{array}$ & $\begin{array}{r}3090 \\
3640 \\
380 \\
\end{array}$ & $\begin{array}{r}43,5 \\
51,2 \\
5,3 \\
\end{array}$ & $\begin{array}{r}570 \\
1930 \\
760 \\
\end{array}$ & $\begin{array}{l}17,5 \\
59,2 \\
23,3\end{array}$ \\
\hline 15 & $\begin{array}{l}\text { сосняк } \\
\text { брусн. }\end{array}$ & $\begin{array}{l}\text { мелкий } \\
\text { средний } \\
\text { кругный }\end{array}$ & $\begin{array}{r}780 \\
1230 \\
2180 \\
\end{array}$ & $\begin{array}{l}18,6 \\
29,5 \\
51,9 \\
\end{array}$ & $\begin{array}{r}660 \\
1490 \\
2790 \\
\end{array}$ & $\begin{array}{l}13,4 \\
30,1 \\
56,5 \\
\end{array}$ & $\begin{array}{l}1440 \\
2720 \\
4970 \\
\end{array}$ & $\begin{array}{l}15,8 \\
29,8 \\
54,4 \\
\end{array}$ & $\begin{array}{r}240 \\
1210 \\
2040 \\
\end{array}$ & $\begin{array}{r}6,9 \\
34,7 \\
58,4 \\
\end{array}$ \\
\hline
\end{tabular}

Характеристика естественного возобновления

Таблица 3 на вырубке из-под ельника черничного

\begin{tabular}{|c|c|c|c|c|c|c|c|c|c|c|c|c|}
\hline \multirow{3}{*}{$\begin{array}{l}\text { Год } \\
\text { иссле- } \\
\text { дова- } \\
\text { ния } \\
\end{array}$} & \multicolumn{11}{|c|}{ Групшы высот, м } & \multirow{3}{*}{$\begin{array}{l}\text { Всего } \\
\text { подроста } \\
\text { ели }\end{array}$} \\
\hline & \multicolumn{2}{|c|}{ до 0,5} & \multicolumn{2}{|c|}{$0,51-1,0$} & \multicolumn{2}{|c|}{$1,01-2,0$} & \multicolumn{2}{|c|}{\begin{tabular}{|r|}
$2,01-3,0$ \\
\end{tabular}} & \multicolumn{2}{|c|}{$3,01-4,0$} & \multirow{2}{*}{\begin{tabular}{|c|}
$\frac{>4,0}{\mathrm{wr} / \mathrm{ra}}$ \\
$\frac{\%}{\%}$
\end{tabular}} & \\
\hline & $\frac{\text { шт/ra }}{\%}$ & лет & $\frac{\underline{\mathbf{m}} / \mathbf{\Gamma a}}{\%}$ & лет & $\frac{\underline{\mathrm{mT}} / \mathrm{\Gamma a}}{\%}$ & лет & $\frac{\text { шт/га }}{\%}$ & лет & $\frac{\underline{\mathrm{\omega T} / \mathrm{\Gamma a}}}{\%}$ & лет & & \\
\hline 1956 & $\frac{890}{37}$ & 8 & $\frac{600}{25}$ & 18 & $\frac{480}{20}$ & 35 & $\frac{190}{8}$ & 63 & $\frac{240}{10}$ & 75 & - & $\frac{2400}{100}$ \\
\hline 1972 & $\frac{110}{5}$ & & $\frac{260}{12}$ & & $\frac{490}{23}$ & & $\frac{340}{16}$ & & $\frac{280}{13}$ & & $\frac{660}{31}$ & $\frac{2140}{100}$ \\
\hline
\end{tabular}

